\title{
Cost-utility of a walking programme for moderately depressed, obese, or overweight elderly women in primary care: a randomised controlled trial
}

\author{
Narcis Gusi*1, Maria C Reyes ${ }^{1}$, Jose L Gonzalez-Guerrero², Emilio Herrera ${ }^{3}$ \\ and Jose M Garcia ${ }^{3}$
}

Address: ${ }^{1}$ Faculty of Sports Sciences, University of Extremadura, Cáceres, Spain, ${ }^{2}$ Geriatric Unite, Hospital of Cáceres, Cáceres, Spain and ${ }^{3}$ Health System of Extremadura, Junta de Extremadura, Mérida, Spain

Email: Narcis Gusi* - ngusi@unex.es; Maria C Reyes - mamenrz48@hotmail.com; Jose L Gonzalez-Guerrero - joselglez@teleline.es;

Emilio Herrera - emilio.herrera@ses.juntaex.es; Jose M Garcia - jmgarciadominguez@yahoo.es

* Corresponding author

Published: 8 July 2008

BMC Public Health 2008, 8:231 doi:I0.II86/|47|-2458-8-231
Received: 30 October 2007

Accepted: 8 July 2008

This article is available from: http://www.biomedcentral.com/I47I-2458/8/23 I

(c) 2008 Gusi et al; licensee BioMed Central Ltd.

This is an Open Access article distributed under the terms of the Creative Commons Attribution License (http://creativecommons.org/licenses/by/2.0), which permits unrestricted use, distribution, and reproduction in any medium, provided the original work is properly cited.

\begin{abstract}
Background: There is a considerable public health burden due to physical inactivity, because it is a major independent risk factor for several diseases (e.g., type 2 diabetes, cardiovascular disease, moderate mood disorders neurotic diseases such as depression, etc.). This study assesses the cost utility of the adding a supervised walking programme to the standard "best primary care" for overweight, moderately obese, or moderately depressed elderly women.
\end{abstract}

Methods: One-hundred six participants were randomly assigned to an interventional group $(\mathrm{n}=$ $55)$ or a control group $(n=5 I)$. The intervention consisted of an invitation, from a general practitioner, to participate in a 6-month walking-based, supervised exercise program with three 50 minute sessions per week. The main outcome measures were the healthcare costs from the Health System perspective and quality adjusted life years (QALYs) using EuroQol (EQ-5D.)

Results: Of the patients invited to participate in the program, $79 \%$ were successfully recruited, and $86 \%$ of the participants in the exercise group completed the programme. Over 6 months, the mean treatment cost per patient in the exercise group was $€ 41$ more than "best care". The mean incremental QALY of intervention was 0.132 (95\% Cl: 0.104-0.286). Each extra QALY gained by the exercise programme relative to best care cost $€ 3 I I \quad(95 \% \mathrm{Cl}, € \mid 43-€ 394)$. The cost effectiveness acceptability curves showed a $90 \%$ probability that the addition of the walking programme is the best strategy if the ceiling of inversion is €350/QALY.

Conclusion: The invitation strategy and exercise programme resulted in a high rate of participation and is a feasible and cost-effective addition to best care. The programme is a costeffective resource for helping patients to increase their physical activity, according to the recommendations of general practitioners. Moreover, the present study could help decision makers enhance the preventive role of primary care and optimize health care resources.

Trial Registration: [ISRCTN9893 I797] 


\section{Background}

Physical inactivity is a considerable public health burden, because it is a major independent risk factor for several diseases (e.g., type 2 diabetes, cardiovascular disease, moderate mood disorders neurotic diseases such as depression, etc.) $[1,2]$. It is also associated with a high prevalence of musculoskeletal disorders [3]. Moderate depression and being overweight are among the most common and expensive public health problems and leading reasons for consultation in primary care [4,5]. A large proportion of health care resources - including office visits, hospitalisation, and medication - are required by the elderly.

General practitioners usually recommend increasing physical activity because even such moderate increases have been shown to improve the quality of life in older adults [6,7] and elderly are interested in sports, walking and health [8]. However, rates of physical inactivity are substantial in elderly women [9-12]. Therefore, physical activity should be promoted, especially in elderly populations. The National Institute for Health and Clinical Excellence (NICE) of the United Kingdom established the need to study the clinical- and cost-effectiveness of pedometers and exercise referrals because there is limited evidence to recommend these interventions based on studies of walking and cycling, especially in trials longer than 12 weeks [13]. Bjorgaas et al. recently reported that the use of a pedometer with weekly monitoring by nurses is effective in physically active patients with diabetes mellitus, but this activity was not sustained in relatively inactive patients with diabetes mellitus type 2 [14].

Traditional community-based exercise referral schemes involve referral from a primary care practitioner to a $10-$ 12 week exercise programme run by local leisure services. These programmes succeed in the short-term $[15,16]$ but are limited in terms of sustainability and impact on health outcomes [15]. From a health economics perspective, just the assessment and advice from an exercise specialist may be appropriate to initiate action. However, the maintenance of increased activity requires further support (technical or societal support by phone or peers). This need was demonstrated in a study that showed that the proportion of participants who maintained an active lifestyle three months after the cessation of 10-week programmes ranged between $7.5 \%$ in the advice-only group and $11-$ $14 \%$ in the leisure centre group or walking group [17]. Walking appears to be as effective as leisure centre classes and is less expensive [17] but there is a lack of knowledge about walking programmes, especially those that add strengthening and stretching exercises. Wormald et al. [18] indicated that the success of the service was highly dependent upon the exercise advisor and that traditional schemes should be broadened to encompass everyday lifestyle activities. However, as health system resources are limited, the decision-maker frequently selects the strategies adopted based on the lowest cost per quality-adjusted life-years (QALY). Cost utility is the ratio of incremental effectiveness of one strategy compared to another (e.g., standard medical practice) measured in QALYs divided by the incremental cost.

The cost and effectiveness of the patient recruitment strategy are among the most relevant determinants of the cost utility of physical activity promotion. However, further research on recruitment from practice-based populations is required $[19,20]$. In addition, among the few cost-utility analyses of exercise interventions in primary care, most involved patients younger than 60 years of age who suffered heart disease or back pain. Thus, the effectiveness of exercise programmes with overweight or moderately depressed, elderly females remains largely unknown.

The purpose of this study was to assess the cost utility of adding to the standard "best care" a supervised walking programme that also included strengthening and stretching exercises The patients involved were elderly females who were overweight or moderately depressed.

\section{Methods \\ Recruitment}

Four general practices in Cáceres (Spain) were recruited to participate in the study. Practices were selected at random, from those with two to five partners, and these practices were not previously conducting an exercise programme or exercise prescription scheme. Of five general practices approached, four agreed to participate. The distances between practices allowed the grouping of participants into two exercise groups.

The population of the catchment area comprised elderly women who consulted one of the family physicians who practiced in one of four public primary care centres participating in this study. Eligible women were aged 60 years and older, suffered from either moderate depression or were overweight, and were capable of walking for more than 25 minutes. Women who scored 6 to 9 points in the 15-item Geriatric Depression Scale were considered moderately depressed [21]. Women who had a body mass index (BMI) of 25 to $39.9 \mathrm{~kg} / \mathrm{m}^{2}$ were considered overweight (overweight or obese type I or II). Patients were excluded if they had poor health (severe obesity or major depression), a debilitating medical condition or a known unstable cardiac condition, attention or comprehension problems (e.g., Alzheimer's, apraxia, global aphasia, and other types of dementia or psychopathology), or the intention of leaving the region. No patients were excluded following enrolment. 
Physicians advised eligible women on the walking programme, called "Exercise Looks After You", as part of a complete health, fitness and nutritional assessment. In fact, the participating physicians previously included general advice in their routine so the additional time and effort required was kept to a minimum because of the practitioners' busy schedules. All participants provided informed consent in writing, and the study was approved by the Bioethics Committee of the University according to the Declaration of Helsinki.

\section{Study design}

Medical practitioners spent 2 weeks at each practice referring patients to researchers. A research assistant, who did not participate in the current investigation, randomised participants to either an intervention group or control group, according to a random numbers table. The flowchart of participants is presented in Figure 1. Consistently,

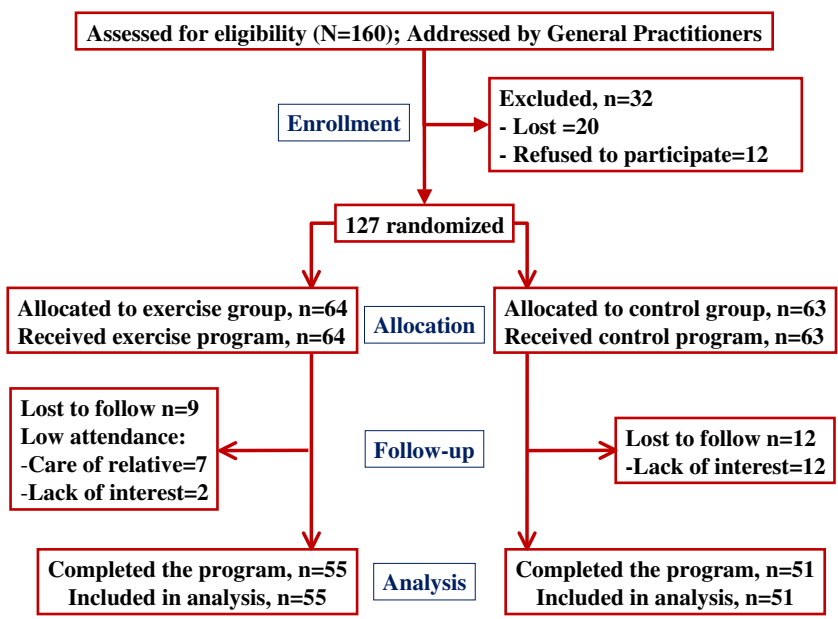

Figure I

Flow-chart of participants throughout trial.

medical practitioners did not know which group patients were randomised to prior to their exercise referral, and they did not interact with the research team throughout the trial. Researchers evaluated participants at baseline and after the 6-month programme.

\section{Interventions}

Two alternatives: best care in general practice and the addition of a walking programme were compared. The research group educated practice teams in "active management" by identifying eligible patients and giving exercise advice.

\section{Exercise programme}

This intervention was a walking programme that consisted of supervised walks with a group in a public park or forest tracks. The qualified exercise leaders had expertise in fitness testing and the supervision of physical activity in groups, and had been graduated from university programs in sport sciences. These leaders instructed and trained the intervention group for 50 minutes, three times per week over a 6-month period. Each session consisted of walking alternating with specific exercises, as follows: 5 minutes of joint mobility (8-12 easy rotations at the neck, shoulder, hip and ankle and 8-12 easy flexion-extensions of the knee, wrist and elbow); 15 minutes of brisk-walking; 5 minutes of strengthening (8-12 flexion-extension of arms against a wall, 8-12 spine flexion with elevation of alternating knees, in a standing position) and stretching (hamstrings and shoulders [trying to touch the fingers on the upper-back]); 20 minutes of brisk-walking including 20 foot-steps and 50 hand-claps to provide additional mechanical impact. In addition, simple nutritional advice was provided. The technicians' schedule included 10 hours per week from Monday to Friday. This programme was designed without reference to any explicit behavioural model or theory; rather, it was intended as a pragmatic intervention that could be easily organised for a large population by a public health agency. The leader neither recommended nor advised against practice between sessions. Socialising within the group was encouraged.

\section{Control group}

Patients in the control group received the best care in general practice, which consisted of routine care and a recommendation of physical activity. These participants in the control group underwent fitness testing by the research team.

\section{Data collection}

Participants completed questionnaires, including the EQ$5 \mathrm{D}$ health status instrument [22] at the beginning of the programme and after the 6-month programme. Over the same period, health care was recorded, including hospital stays, drug usage, secondary care, primary care and physical therapist visits; health care from private resources and within the National Health System was recorded.

\section{Unit costs}

Participants were retired and living close to practices, and were recruited in a previously arranged consultation without considering the current project; thus, we decided to perform an economic analysis from the health service perspective. This decision was based on the assumption that marginal societal costs were negligible (there were no additional costs of displacement, and participants did not lose work-hours). In fact, this analysis were recommended 
by NICE to contribute to health policy for an expensive condition. The unit costs are expressed in Euros at 2005 prices. Participants' follow-up periods were between January and July of the same year. Costs were not adjusted or discounted, as we solely focused on effects over a 6-month period. The cost of the programme was based on the salary of a graduate in sports science in health promotion; this salary was published in the official 2005 bulletin of the regional government. The cost of the programme did not include other possible costs because the clinical analysis did not show statistically significant changes in the use of the National Health System (medication, consultation, etc.) and there was no difference between groups regarding assessment and advice from a physician. In addition, we did not hire any facility (but used public parks or forest tracks), and the recruitment did not require any additional time by the practitioner.

\section{Health outcomes}

The EQ-5D [22] was used to assess five dimensions of health related quality of life (HRQOL): (1) mobility; (2) self-care; (3) daily activities; (4) pain and discomfort; and (5) anxiety or depression. The scale of dimensions is from 1 to 3 (no problems, some problems, or extreme problems). Using a combination of these dimensions, a total of 243 possible health states exist. Each health state has been previously defined using the time trade-off method of utility analysis based on the response of a sample of the Spanish population [23]. This total score of utility was scaled from $1=$ a fully functional quality of life to $0=$ death. The QALYs that the participants experienced over the 6-month period was estimated by calculating "areas under (health utility) curves" [24]. To avoid bias, data were adjusted for differences in baseline EQ-5D scores by regression analysis [25]. The State-Trait Anxiety Inventory (STAI) [26], was used to evaluate anxiety by using 20 items with a scale of 0 to 3 . The Trait Anxiety index is the sum of these 20 scores expressed as a percentage. The fifth questionnaire, the Geriatric Depression Scale [27], includes 15 questions to evaluate the level of depression from 0 (no depression) to 15 (the worst level of depression). A score of 5 or higher indicates the presence of depression.

\section{Sample size}

The primary outcome was the EQ-5D utility. The required sample size was calculated with the Spanish EQ-5D data set for a hypothetical study comparing two groups with a significance level alpha $(0.05)$ and $80 \%$ of the power needed for a minimal clinically relevant difference of 0.1 [28]. The required sample ranges between 60 participants extracted from general population and 100 extracted from critically ill participants. We selected at least 120 participants to exceed the higher number by $20 \%$, thus allowing for potential drop-outs.

\section{Statistical analysis}

The statistical analysis was performed by researchers who had not participated in the data collection or implementation of the exercise programme. Normality of data was initially tested using the Kolgomorov-Smirnov test using the correction of Lillifors. The effects of programme on anxiety, depression and Body Mass Index were tested using analyses of variance (ANOVA) for continuous variables. Age-adjusted analyses of covariance were used to compare, between the groups, the changes in measured variables over time (from the beginning of the programme to 6 months). For all tests the significance level was set at $\mathrm{p}<.05$. The analyses were done using SPSS 15.0 (SPSS Inc. Chicago, USA).

\section{Cost utility analysis}

Most of the participants who dropped out declined to be tested after the period of intervention, so the research team performed a non-intent-to-treat analysis. We first estimated the incremental mean costs of the programme and the mean QALYs gained by the two treatment alternatives. Secondly, the incremental cost effectiveness ratio for the intervention was calculated by dividing the incremental costs by incremental QALYs.

To report the uncertainty due to sampling variation, we calculated the $95 \%$ confidence interval (CI) using the non-parametric bootstrapping technique (1000 replicates re-sampled with replacement from treatment and control populations) and plotted a cost effectiveness acceptability curve $[29,30]$. This curve estimates the probability that the intervention is cost effective compared with the alternative, across the range of values that decision makers pay to achieve an additional QALY. The "investment ceiling" is the level of spending that should not be exceeded, even assuming unlimited funding. For the health care system in Spain, the 2005 adjusted investment ceiling was set at 34729/QALY [31]. Decision makers should compare this upper limit of acceptable payment with estimated incremental cost effectiveness ratios to determine whether a given treatment is cost effective relative to the alternatives.

In addition, two cost effectiveness acceptability curves were plotted to compare the following three different alternatives or scenarios with certain variables manipulated: (A) best care, followed by exercise plus fitness and health assessment at the Physical Activity Unit; (B) best care followed by the worst case scenario (in terms of salary, rate of participation, and efficacy); (C) the walking programme.

Four sensitivity analyses were performed to explore the robustness of estimations and how dependent the results were on estimates of unit costs per participant and efficacy. The first analysis examined the influence of the rate 
of participation in the programme since this could influence the technician's "productivity" based on the number of participants per unit of time provided by the technician. The second analysis estimated the cost of adding a permanent timetable of consultation, assessment or recruitment provided by the technician. To randomise all participants, the present trial only recruited participants prior to the beginning of the exercise programme; however, the widespread implementation of the programme would probably require permanent consultation. We estimated that exercise advisor schedule should increase 5 hours per week to attend the participants and new candidates to join the programme.

A third analysis explored the variations due to the salary changes of the technician since such changes are a major source of variability in economic studies [32].

Finally, the robustness of cost effectiveness was examined by exploring scenarios combining the influence of the variations in salary, rate of participation, and effectiveness from the lowest to the highest limit of the 95\% CI.

\section{Results}

\section{Response}

Seventy-nine percent $(127 / 160)$ of patients identified by general practitioners were recruited, but 20 of referred patients did not follow this referral; they were lost to follow-up or did not come to the research laboratory (Fig. 1). Eighty-six percent (55 of 64) of the participants in the walking group completed the programme. Fifteen to 22 patients attended each exercise group. At baseline, the intervention group was slightly less depressed, less overweight and younger than the control group, but these dif- ferences were not statistically significant $(\mathrm{p}>.05)$ (Table 1 ). The participants who were lost to follow-up (mainly because they had to care for a relative) were similar to those who completed the trial but a slightly higher percentage of them were moderately depressed. The participants in the control group who dropped out were similar to those who followed the trial but they were mainly living in an urban area. The social network in the rural area was stronger. Anxiety and depression, as measured by the EQ-5D, STAI and Geriatric Depression Scale, improved in the intervention group and mean BMI decreased (BMI mean change $1.2 \%$; $=.003$ ); these measures in the control group remained unaltered for the most part (Table 2).

\section{Costs}

The incremental cost of adding the exercise programme (Table 3), 2250, was related to the salary of the technician (10 hours per week; $25 \%$ of the total salary) over a 6 month period. Therefore, the mean incremental cost per participant, integrated in a group smaller than 30 participants, who attended three of the five available sessions per week, was 41.

\section{Health outcome and cost utility analysis}

The interventional group improved more QALYs than the control group (Table 4) being adequate to perform a cost utility analysis. Each additional QALY gained by the exercise group cost less than 400. The cost effectiveness acceptability curves (Fig. 2) showed a $99.9 \%$ probability that the addition of the walking programme is an acceptable strategy if the ceiling of inversion is 600/QALY.

Table I: Baseline characteristics of patients allocated exercise programme or best care.

\begin{tabular}{|c|c|c|c|c|}
\hline Characteristics & $\begin{array}{r}\text { Exercise } \\
\text { Completed } \\
\text { Follow up }\end{array}$ & $\begin{array}{r}\text { Best Care } \\
\text { Completed } \\
\text { Follow up }\end{array}$ & $\begin{array}{r}\text { Exercise } \\
\text { Lost to } \\
\text { Follow up }\end{array}$ & $\begin{array}{l}\text { Best Care } \\
\text { Lost to } \\
\text { Follow up }\end{array}$ \\
\hline $\mathrm{N}$ & 55 & 51 & 9 & 12 \\
\hline Age (years) & $7 I(5)$ & $74(6)$ & & \\
\hline Living in rural areas (\%) & 67 & 65 & 67 & 33 \\
\hline Living alone (\%) & 24 & 18 & 22 & 17 \\
\hline Education, primary school or higher (\%) & 40 & 37 & 44 & 33 \\
\hline \multicolumn{5}{|l|}{ Income (€/month), (\%): } \\
\hline less than 360 & 4 & 3 & 11 & 0 \\
\hline 360 to 600 & 89 & 91 & 89 & 92 \\
\hline more than 600 & 7 & 6 & 0 & 8 \\
\hline Daily smoking (I or more cigarette/day) & I & 0 & 0 & 0 \\
\hline Daily alcohol consumption (\%) & II & 4 & & \\
\hline Physical activity standardised (\%) & 0 & 0 & 0 & 0 \\
\hline Overweight (\%) & 80 & 86 & 78 & 83 \\
\hline BMI & $29.7(4.2)$ & $30.6(4.3)$ & & \\
\hline Diabetes mellitus type II (\%) & 40 & 39 & 33 & 25 \\
\hline Moderate depressed (\%) & 33 & 39 & 44 & 33 \\
\hline
\end{tabular}


Table 2: Health outcomes of the exercise programme compared to usual care

\begin{tabular}{|c|c|c|c|c|}
\hline Health outcome & Group & Baseline & Six months & $p^{*}$ \\
\hline \multirow[t]{2}{*}{ Body Mass Index $\left(\mathrm{kg} \cdot \mathrm{m}^{-2}\right)$} & exercise & $29.7(4.2)$ & $29.4(4.2)$ & .003 \\
\hline & Control & $30.6(4.3)$ & $30.8(4.3)$ & \\
\hline \multirow[t]{2}{*}{ Depression by Geriatric Depression Scale } & Exercise & $2.3(2.5)$ & $1.8(2.3)$ & .001 \\
\hline & Control & $2.6(2.5)$ & $2.9(2.5)$ & \\
\hline \multirow[t]{2}{*}{ Anxiety by State Trait Anxiety Inventory } & exercise & $19.2(I 1.2)$ & $14.1(9.0)$ & $<.001$ \\
\hline & Control & $21.2(10.4)$ & $22.2(9.8)$ & \\
\hline \multirow{2}{*}{ Anxiety/Depression by EQ-5D } & Exercise & $1.4(0.6)$ & $1.2(0.4)$ & .009 \\
\hline & Control & $1.4(0.6)$ & $\mathrm{I} .5(0.7)$ & \\
\hline
\end{tabular}

*p of $\mathrm{F}$ by Analysis of Variance.

\section{Sensitivity analysis}

The sensitivity analyses are presented in Table 5. The first analysis manipulated the number of participants and their distribution in groups attended by the technician. This analysis showed a variation of cost-utility ratio from

311 to 462/QALY. In the second analysis, the predicted cost-utility of adding 5 hours per week, to assess and recruit new participants, was 462/QALY. The third sensitivity analysis focused on salary since this is a major source of cost variation related to location. If the salary was doubled the cost utility ratio was 621/QALY. The fourth analysis presented the best scenario or combination of the previously cited variables and the worst scenario. The estimated cost utility ratio ranged between 94/ QALY of the best scenario and 871/QALY of the worst scenario.

\section{Discussion \\ Principal findings}

The present study demonstrated that practitioners' exercise advice and the walking-programme efficiently enhanced the health-related quality of life in a high risk population, overweight or moderately depressed elderly women. This efficiency was based upon low-cost; however, a high recruitment rate was obtained by combining the medical advice of practitioners with the supervision of an exercise monitor.

\section{Strengths and weakness}

To our knowledge, the current study is the first cost utility analysis of a walking exercise intervention with elderly females in primary care. It differed from traditional exercise referral schemes in that the physical activity advisors were specifically trained and employed for this programme [18]. In addition, walking, as well as strengthening and stretching exercises were used to enhance the feasibility of the programme in different environments. The most comparable study, by Munro et al. [33], analysed the cost utility of a strategy based on a letter from the research team inviting physically untrained persons older than 65 years of age to attend locally organised, free, twice weekly, exercise classes for 2 years. That study was conducted in Great Britain and the authors reported an incremental cost of 17174/QALY gained, using the utility index from the SF-36 and a mean cost per attendee per session of 9.1. In the present study we calculated an incremental cost of 311/QALY and 0.5/attendee per session. The differences between the study by Munro et al. and our study may be partly explained by: (a) the lower initial QALY in our population; (b) the gender of participants, who were predominantly female in the Munro study but exclusively female in our study; (c) the lengths of the programmes ( 2 years in the Munro study and 6 months in our study); and (d) the greater expense of the recruitment strategy of Munro et al. However, the impact of differences in programme length may (c, above) may have been minimized because most of the QALY increments in the

Table 3: Incremental cost of the exercise programme compared to usual care.

\begin{tabular}{lrr}
\hline Concept & unit* & over 6 months $(€)$ \\
\hline Health system costs & & Total $(€)$ \\
Personnel $\dagger$ & & \\
$\quad$ sport technician $(25$ weeks) & $9 € /$ hour & 2250 \\
Facilities (renting) & $0 € /$ hour & 0 \\
Medication (no mean change were observed) & Drug price & 0 \\
Consultation (no mean change were observed) & Official price & 0 \\
Total health system perspective & & 2250
\end{tabular}

- *Public cost in Euro in 2005.

† There is no marginal cost of adding or dropping-out participants in groups up to 30 persons. 
Table 4: The EQ-5D utilities of the exercise programme compared to usual care

\begin{tabular}{lrr}
\hline Alternatives & $\begin{array}{r}\text { Best care in general } \\
\text { Practice }(n=5 I)\end{array}$ & $\begin{array}{r}\text { Best care plus } \\
\text { Exercise }(n=55)\end{array}$ \\
\hline EQ-5D utility at baseline & $0.542(0.334)$ & $0.688(0.304)$ \\
EQ-5D utility at 6 months* & $0.510(0.196)$ & $0.890(0.178)$ \\
QALY over 6 months* & $0.263(0.132)$ & $0.395(0.121)$ \\
QALY difference versus best care† & & $0.132(0.104$ to 0.286$)$ \\
Incremental cost per person $(€)$ & $4 I$ \\
Cost-utility $(€ / Q A L Y) \dagger$ & & $31 I(143$ to 394) \\
\hline
\end{tabular}

Expressed as mean (SD)

QALY = quality adjusted life year

*Mean (SD) estimated by analysis of covariance with adjustment for baseline EQ-5D score and then rounded to three significant figures.

† Mean ( $95 \%$ confidence interval estimated by bootstrapping).

Munro study were achieved in the first part of the 2-year period.

Previous studies have shown that recruiting elderly people in the general population to participate in exercise proves difficult, even when using different strategies $[34,35]$. In the framework of practice-based recruitment, Margitic et al. [19] reported that patient self-administered, officebased questionnaires were cheaper ( $\$ 14 /$ randomized participant) than patient mailings (\$58) and direct telephone contact. Direct medical invitations to an exercise unit or office are easier to administer and less expensive; however, the rate of recruitment varies. Tully et al. [36] reported poor recruitment following contact by the general practitioner who invited patients to participate in an unsupervised home-based walking programme. Stevens et

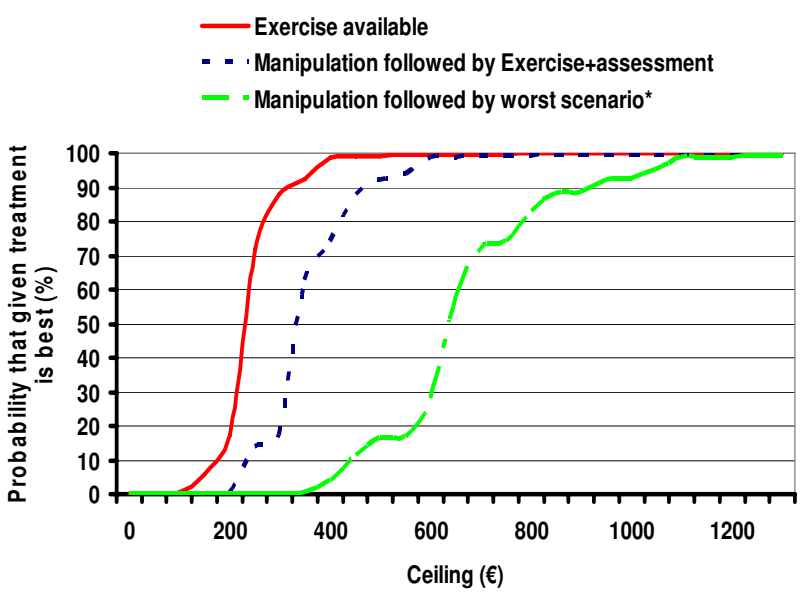

\section{Figure 2}

Cost effectiveness acceptability curves. * Worst scenario described as $30 \%$ higher salary, $30 \%$ lower participation rating and the effectiveness of lower limit of $95 \%$ confidence interval. - The efficiency threshold was set at $34729 € /$ QALY. al. [20] achieved higher recruitment rates by inviting patients (45-74 years of age) to a consultation with an exercise development officer and offering a personalised combination of leisure-centre and home-based activities. However, our sensitivity analysis suggests that unit costs could be halved with a more effective recruitment strategy. Bell-Syer and Moffet [37] reported a 73\% response rate to general practitioner reiterative invitations (an average of seven invitations) to participate in an exercise program for primary care patients with low-back pain. A recent review of exercise referrals in the United Kingdom [17] reported similar rates of recruitment by mail (50-60\%) and low rates of maintenance without the continuous support of a technician. The strategy in the current study resulted in a recruitment rate of $79 \%$; this strategy consisted of a specific targeted invitation from general practitioners to elderly women who were overweight or moderately depressed, offering a consultation with an exercise monitor and a supervised exercise programme. This high recruitment rate could be partially explained by the specificity of the invitation to older, overweight patients, who are usually more willing to participate than the general population [38], the active-management of general practitioners [39], and the offer of supervision in the exercise programme. Richert et al. [40] also demonstrated benefits of partnership and natural peer support in low-cost recruiting for enhancing physical activity. While recruitment rates were high in our programme, the retention rate of $86 \%$ was similar to previous supervised, group-based community strategies to promote exercise in the elderly population (80-90\%) [6].

The NICE of the United Kingdom has recommended telephone support as an inexpensive alternative for maintaining the physically active lifestyle acquired by exercise referrals. However, more research is required to assess the comparative sustainability, retention, effectiveness and cost-effectiveness of exercise programmes (walking, cycling, advising or pedometer) that are longer than 10 weeks [14]. Benett et al. [41] has recently reported that the 
Table 5: Sensitivity analyses by treatment group

\begin{tabular}{|c|c|c|}
\hline Manipulation of variables & $\begin{array}{l}\text { Incremental cost versus } \\
\text { best care per person }(€)\end{array}$ & $\begin{array}{r}\text { Cost utility ratio } \\
(€ / Q A L Y)\end{array}$ \\
\hline \multicolumn{3}{|l|}{ Number of participants: } \\
\hline - $30 \%$ lower & 58 & 439 \\
\hline - 30\% higher* & 47 & 356 \\
\hline$-50 \%$ lower or higher & 41 & 311 \\
\hline - Distributed in 3 groups* & 61 & 462 \\
\hline Including $5 \mathrm{~h} /$ week for assessment & 61 & 462 \\
\hline \multicolumn{3}{|l|}{ Salary of technician: } \\
\hline - $30 \%$ lower & 29 & 220 \\
\hline - $30 \%$ higher & 54 & 409 \\
\hline $\begin{array}{l}\text { Best scenario of salary, } \\
\text { participation and effectiveness } \dagger\end{array}$ & 27 & 94 \\
\hline $\begin{array}{l}\text { Worst scenario of salary, } \\
\text { participation and effectivenessł }\end{array}$ & 115 & 871 \\
\hline
\end{tabular}

* Requires 5 additional hours of the technician

†Salary $30 \%$ lower + Participation 30 persons per group + QALY differential at higher limit of $95 \%$ confidence interval + distributed in two groups

$\ddagger$ Salary $30 \%$ higher + Participation 30\% lower + QALY differential at lower limit of $95 \%$ confidence interval + distributed in three groups.

combination of a pedometer-based exercise program with monthly telephone support did not increase the level of physical activity in physically inactive persons. However, evidence suggests that the pedometer-based programme works well with more physically active persons $[14,42]$.

\section{Unanswered questions}

Exercise programmes targeted towards patients with particular diseases result in a demonstrable reduction in the use of health care services (frequentation, medication, etc.) $[17,43,44]$; however, exercise programmes targeted towards the general population have not been found to make any difference in the use of health care services in primary care [33]. The current study also failed to find changes in the use of primary health care services. The sample size was adequate to test the primary outcome, the utility of EQ-5D, but the sample size may have been insufficient to detect significant changes in the use of health services and medication. This relative reduction in the sample size was partially due to the selection criteria, which excluded patients with co-morbidities to allow us to focus the study on women with obesity and depression. The effects of the current programme on health system resources in a more wide-spread service could vary. However, the lack of change in frequency of consultations (consultation/month) in the short-term may be partially explained by the limits of supply and the management of "free" appointments in the general practices of the National Health System. Therefore, one should be cautious in generalizing these results to private care or more wide-spread services. In addition, this study may have been limited by a selection bias that favoured patients with low educational levels and low income, and who lived in medium sized cities and rural areas. As a result, more research is required to assess the efficiency of the current strategy in a more general population, with a longer programme, in different age or socioeconomic groups. The largest effect using the EQ-5D was detected in the dimension of anxiety/depression, so one could expect better cost-utility ratios in groups that include higher percentages of participants with problems in anxiety/depression.

\section{Conclusion}

The current study presented a pragmatic and cost-effective strategy to enhance the level of physical activity in overweight or moderately depressed elderly women. The programme could be a cost-effective resource for helping patients increase physical activity, as recommended by general practitioners. Moreover, the present study could help decision makers enhance the preventive role of primary care and optimize health resources.

\section{List of abbreviations}

BMI, body mass index; NICE, National Institute for Health and Clinical Excellence; QALY, quality-adjusted life years

\section{Competing interests}

The authors declare that they have no competing interests.

\section{Authors' contributions}

NG was involved in the conception, planning and design of this study, as well as the acquisition of data (but not the fitness testing), analysis and interpretation of data, and writing the manuscript. MCR was involved in organising this research, the acquisition of data and analysis and interpretation of data. JLG and JMG were involved in 
planning and organising the research and interpretation of data. EH assisted in the writing of the manuscript. All the authors read and approved the final manuscript.

\section{Acknowledgements}

Thanks to Angeles Duran and Yolanda Garcia for their technical support. The study was supported by European Social Funds and the Government of Extremadura, Spain (2PR02B0I7).

\section{References}

I. Allender S, Foster C, Scarborough P, Rayner M: The burden of physical activity-related ill health in the UK. Journal of epidemiology and community health 2007, 6 I (4):344-348.

2. Bassuk SS, Manson JE: Epidemiological evidence for the role of physical activity in reducing risk of type 2 diabetes and cardiovascular disease. J Appl Physiol 2005, 99(3): I 193-1204.

3. Morken T, Mageroy N, Moen BE: Physical activity is associated with a low prevalence of musculoskeletal disorders in the Royal Norwegian Navy: a cross sectional study. BMC musculoskeletal disorders 2007, 8:56.

4. Frost GS, Lyons GF: Obesity impacts on general practice appointments. Obesity research 2005, I 3(8): | $442-1449$.

5. Smith K, Shah A, Wright K, Lewis G: The prevalence and costs of psychiatric disorders and learning disabilities. $\mathrm{Br} J$ Psychiatry 1995, 166(I):9-18.

6. King AC, Rejeski WJ, Buchner DM: Physical activity interventions targeting older adults. A critical review and recommendations. American journal of preventive medicine 1998, I5(4):316-333.

7. Guallar-Castillon P, Santa-Olalla Peralta P, Banegas IR, Lopez E, Rodriguez-Artalejo F: Physical activity and quality of life in older adults in Spain. Medicina clinica 2004, 123(16):606-610.

8. Gusi N, Prieto J, Forte D, Gomez I, Gonzalez-Guerrero J: Needs, interests, and limitations for the promotion of health and exercise: a web site for sighted and blind elderly people. Educational Gerontology 2008, 34: I- I3.

9. Tormo MJ, Navarro C, Chirlaque MD, Barber X, Argilaga S, Agudo A, Amiano P, Barricarte A, Beguiristain JM, Dorronsoro M, et al.: Physical sports activity during leisure time and dietary intake of foods and nutrients in a large Spanish cohort. Int J Sport Nutr Exerc Metab 2003, I3(I):47-64.

10. Santos R, Aires L, Santos P, Ribeiro JC, Mota J: Prevalence of overweight and obesity in a Portuguese sample of adults: Results from the Azorean Physical Activity and Health Study. Am J Hum Biol 2008, 20(1):78-85

II. Mota J, Lacerda A, Santos MP, Ribeiro JC, Carvalho J: Perceived neighborhood environments and physical activity in an elderly sample. Percept Mot Skills 2007, I 04(2):438-444.

12. Rutten $A$, Abel $T$, Kannas $L$, von Lengerke $T$, Luschen $G$, Diaz JA Vinck J, Zee J van der: Self reported physical activity, public health, and perceived environment: results from a comparative European study. Journal of epidemiology and community health 200I, 55(2): I39-146.

13. Excellence NifHaC: Four commonly used methods to increase physical activity: brief interventions in primary care, exercise referral schemes, pedometers and community-based exercise programmes for walking and cycling London: National Institute for Health and Clinical Excellence; 2006.

14. Bjørgaas M, Vik J, Stølen T, Lydersen S, Grill V: Regular use of pedometer does not enhance beneficial outcomes in a physical activity intervention study in type 2 diabetes mellitus. Metabolism 2008, 57:605-6II.

15. Harrison RA, Roberts C, Elton PJ: Does primary care referral to an exercise programme increase physical activity one year later? A randomized controlled trial. Journal of public health (Oxford, England) 2005, 27(I):25-32

16. Pazoki R, Nabipour I, Seyednezami N, Imami SR: Effects of a community-based healthy heart program on increasing healthy women's physical activity: a randomized controlled trial guided by Community-based Participatory Research (CBPR). BMC public health 2007, 7:216.

17. Isaacs A, Critchley J, Tai S, Buckingham K, Westley D, Harridge S, Smith C, Gottlieb J: Exercise Evaluation Randomised Trial
(EXERT): a randomised trial comparing GP referral for leisure centre-based exercise, community-based walking and advice only. Health technology assessment (Winchester, England) 2007, II:I-I65.

18. Wormald H, Waters H, Sleap M, Ingle L: Participants' perceptions of a lifestyle approach to promoting physical activity: targeting deprived communities in Kingston-upon-Hull. BMC public health 2006, 6:202.

19. Margitic S, Sevick MA, Miller M, Albright C, Banton J, Callahan K, Garcia M, Gibbons L, Levine BJ, Anderson R, et al.: Challenges faced in recruiting patients from primary care practices into a physical activity intervention trial. Activity Counseling Trial Research Group. Preventive medicine 1999, 29(4):277-286.

20. Stevens W, Hillsdon M, Thorogood M, McArdle D: Cost-effectiveness of a primary care based physical activity intervention in 45-74 year old men and women: a randomised controlled trial. British journal of sports medicine 1998, 32(3):236-24I.

21. Martinez J, Onis M, Duenas R, Colomer C, Aguado C, Luque R: The Spanish version of the Yesavage abbreviated questionnaire (GDS) to screen depressive dysfunctions in patients older than 65 years. MEDIFAM 2002, 12:620-630.

22. Herdman M, Badia X, Berra S: EuroQol-5D: a simple alternative for measuring health-related quality of life in primary care. Atencion primaria/Sociedad Espanola de Medicina de Familia y Comunitaria 200I, 28(6):425-430.

23. Badia X, Roset M, Montserrat S, Herdman M, Segura A: The Spanish version of EuroQol: a description and its applications. European Quality of Life scale. Medicina clinica 1999, I I2(SuppI I):79-85.

24. Matthews JN, Altman DG, Campbell MJ, Royston P: Analysis of serial measurements in medical research. $B M$ ) (Clinical research ed) 1990, 300(67 19):230-235

25. Manca A, Hawkins N, Sculpher MJ: Estimating mean QALYs in trial-based cost-effectiveness analysis: the importance of controlling for baseline utility. Health economics 2005, I4(5):487-496.

26. Spielberger C, Gorauch R, Luschene R: State-Trait Anxiety Inventory, Spanish Madrid: TEA; 1982.

27. Marti D, Miralles R, Llorach I: Depressive alterations in a convalescence unit: experience and validation of the Spanish version of Yesavage Geriatric Scale. Rev Esp Geriatr Gerontol 2000, 35:7-I4

28. Roset M, Badia X, Mayo NE: Sample size calculations in studies using EuroQol 5D. Quality of Life Research 1999, 8:539-549.

29. Fenwick E, Byford S: A guide to cost-effectiveness acceptability curves. Br J Psychiatry 2005, 187:106-108.

30. Willan AR: On the probability of cost-effectiveness using data from randomized clinical trials. $B M C$ medical research methodology 200I, I:8.

31. Sacristan J, Oliva J, Del Llano J, Prieto L, Pinto J: What is an efficient health technology in Spain? Gac Sanit 2002, 16:334-343.

32. Sculpher MJ, Pang FS, Manca A, Drummond MF, Golder S, Urdahl H, Davies LM, Eastwood A: Generalisability in economic evaluation studies in healthcare: a review and case studies. Health Technol Assess 2004, 8(49):iii-iv. I-192

33. Munro J, Brazier J, Davey R, Nicholl J: Physical activity for the over-65s: could it be a cost-effective exercise for the NHS? Journal of public health medicine 1997, 19(4):397-402.

34. Sevick MA, Dunn AL, Morrow MS, Marcus BH, Chen G], Blair SN: Cost-effectiveness of lifestyle and structured exercise interventions in sedentary adults: results of project ACTIVE. American journal of preventive medicine 2000, I (1): I-8.

35. Stiggelbout M, Hopman-Rock M, Tak E, Lechner L, van Mechelen W: Dropout from exercise programs for seniors: a prospective cohort study. J Aging Phys Act. 2005, 13(4):406-42I

36. Tully MA, Cupples ME, Chan WS, McGlade K, Young IS: Brisk walking, fitness, and cardiovascular risk: a randomized controlled trial in primary care. Preventive medicine 2005, 4 I (2):622-628.

37. Bell-Syer SE, Moffett JA: Recruiting patients to randomized trials in primary care: principles and case study. Family practice 2000, I7(2): $187-191$.

38. Farrin A, Russell I, Torgerson D, Underwood M: Differential recruitment in a cluster randomized trial in primary care: the experience of the UK back pain, exercise, active management and manipulation (UK BEAM) feasibility study. Clinical trials (London, England) 2005, 2(2): I I9-I24. 
39. Chinn DJ, White M, Howel D, Harland JO, Drinkwater CK: Factors associated with non-participation in a physical activity promotion trial. Public health 2006, I 20(4):309-3I9.

40. Richert ML, Webb AJ, Morse NA, O'Toole ML, Brownson CA: Move More Diabetes: using Lay Health Educators to support physical activity in a community-based chronic disease self-management program. The Diabetes educator 2007, 33(Suppl 6): $1795-184 S$.

4I. Bennett J, Young H, Nail L, Winters-Stone K, Hanson G: A telephone-only motivational intervention to increase physical activity in rural adults: a randomized controlled trial. Nurs Res 2008, 57:24-32.

42. Gemson DH CR, Fuente J, Newman J, Benson S: Promoting weight loss and blood pressure control at work: impact of an education and intervention program. J Occup Environ Med 2008, 50:272-28I.

43. Geraets ]J, Goossens ME, de Bruijn CP, de Groot IJ, Koke AJ, Pelt RA, Heijden G Van der, Dinant GJ, Heuvel WJ van den: Cost-effectiveness of a graded exercise therapy program for patients with chronic shoulder complaints. International journal of technology assessment in health care 2006, 22(1):76-83.

44. Korthals-de Bos IB, Hoving JL, van Tulder MW, Rutten-van Molken MP, Ader H], de Vet HC, Koes BW, Vondeling H, Bouter LM: Cost effectiveness of physiotherapy, manual therapy, and general practitioner care for neck pain: economic evaluation alongside a randomised controlled trial. BMJ (Clinical research ed) 2003, 326(7395):911.

\section{Pre-publication history}

The pre-publication history for this paper can be accessed here:

http://www.biomedcentral.com/1471-2458/8/231/pre pub

Publish with Biomed Central and every scientist can read your work free of charge

"BioMed Central will be the most significant development for disseminating the results of biomedical research in our lifetime. "

Sir Paul Nurse, Cancer Research UK

Your research papers will be:

- available free of charge to the entire biomedical community

- peer reviewed and published immediately upon acceptance

- cited in PubMed and archived on PubMed Central

- yours - you keep the copyright 